\title{
Investigation of central versus peripheral effects of estradiol in ovariectomized mice
}

\author{
Niklas Andersson ${ }^{*}{ }^{1}$, Ulrika Islander ${ }^{*}$, Emil Egecioglu ${ }^{3}$, Elin Lö ${ }^{4}$, \\ Charlotte Swanson ${ }^{1}$, Sofia Movérare-Skrtic ${ }^{1}$, Klara Sjögren ${ }^{1}$, \\ Marie K Lindberg ${ }^{1}$, Hans Carlsten ${ }^{2}$ and Claes Ohlsson ${ }^{1}$
}

${ }^{1}$ Center for Bone Research at the Sahlgrenska Academy, Division of Endocrinology, Department of Internal Medicine, Göteborg University, Gröna stråket 8 SE-413 45 Göteborg, Sweden

${ }^{2}$ Department of Rheumatology and Inflammation Research at the Sahlgrenska Academy, Göteborg University, Guldhedsgatan 10 , SE-413 46 Göteborg, Sweden

${ }^{3}$ Department of Physiology, Göteborg University, Medicinaregatan 9, Box 434 SE-405 30 Göteborg, Sweden

${ }^{4}$ Department of Pharmacology, Göteborg University, Medicinaregatan 9, Box 434 SE-405 30 Göteborg, Sweden

(Requests for offprints should be addressed to N Andersson; Email: niklas.andersson@medic.gu.se)

${ }^{*} \mathrm{~N}$ Andersson and $\mathrm{U}$ Islander contributed equally to this work

\begin{abstract}
It is generally believed that estrogens exert their bone sparing effects directly on the cells within the bone compartment. The aim of the present study was to investigate if central mechanisms might be involved in the bone sparing effect of estrogens. The dose-response of central (i.c.v) 17 $\beta$-estradiol (E2) administration was compared with that of peripheral (s.c.) administration in ovariectomized (ovx) mice. The dose-response curves for central and peripheral E2 administration did not differ for any of the studied estrogen-responsive tissues, indicating
\end{abstract}

that these effects were mainly peripheral. In addition, ovx mice were treated with E2 and/or the peripheral estrogen receptor antagonist ICI 182,780. ICI 182,780 attenuated most of the estrogenic response regarding uterus weight, retroperitoneal fat weight, cortical BMC and trabecular bone mineral content $(P<0 \cdot 05)$. These findings support the notion that the primary target tissue that mediates the effect of E2 on bone is peripheral and not central.

Journal of Endocrinology (2005) 187, 303-309

\section{Introduction}

Estrogens are of importance for the regulation of bone metabolism in both males and females. It is generally believed that estrogens exert their bone sparing effects directly on the cells within the bone compartment. However, some studies indicate that the effects of estrogens on bone might be indirect and mediated via other tissues (Vanderschueren et al. 2004). An indirect mechanism is supported by the fact that the effects of estrogens in vitro on cultured osteoblasts/osteoclasts, are often small and sometimes only seen when the cells are transfected with a high number of estrogen receptors (Vanderschueren et al. 2004), while the in vivo effects of estrogens on bone are more pronounced (Clark et al. 2004). In addition, the bone sparing effect of estrogens on bone is partly lost after hypophysectomy (Yeh et al. 1997) and it has been suggested that estrogens increase bone mass partly through the stimulation of pituitary growth hormone secretion (Vanderschueren et al. 2004). Furthermore, it has been suggested that the hypothalamus might be of importance in the regulation of not only fat mass but also bone mass, and that osteoporosis may at least in part be a hypothalamic disease (Baldock et al. 2002, Takeda et al. 2002). Animal experiments have shown that the inactivation of central leptin receptors (Takeda et al. 2002), or of hypothalamic neuropeptide Y Y2 receptors (Baldock et al. 2002), resulted in increased bone mass. It was proposed that activation of either of these receptors causes a tonic inhibition of bone mass. Furthermore, we have recently demonstrated that inactivation of another hypothalamic receptor, the melanin concentrating hormone receptor-1, results in decreased bone mass (Bohlooly et al. 2004), further supporting the notion that the hypothalamus is an important target organ and sensor for factors regulating bone mass. Thus, one may speculate that the effects of estrogens on bone might include hypothalamic mechanisms. In a previous preliminary investigation, it was indicated that the pituitary gland might be involved in the estrogenic effect on bone. Estrogen treatment to rats that were both hypophysectomized and ovariectomized (ovx) did not result in any beneficial effects on bone mass, 
suggesting that a pituitary product is either obligatory or a critical co-factor for estrogen-related effects on bone (Bryant et al. 1994).

The aim of the present study was to investigate the relative contribution of peripheral versus central estrogen receptors in the mediation of the effects of $17 \beta$-estradiol (E2) on bone and on some other estrogen-responsive tissues. Two different approaches were used to investigate the relative importance of estrogen receptors in the peripheral versus central estrogen receptors. We first compared the dose-response of central E2 administration with that of peripheral E2 administration in ovx mice. In addition, ovx mice were treated with $\mathrm{E} 2$ and/or the peripheral estrogen receptor antagonist ICI 182,780. We demonstrate that the primary target tissue for that mediates the effect of E2 on bone is peripheral and not central.

\section{Material and Methods}

Animals

Female C57BL/6 mice were used in all experiments (Taconic M\&B, Skensved, Denmark). The animals were maintained under a strict $12 \mathrm{~h}$ light: $12 \mathrm{~h}$ darkness cycle at $22{ }^{\circ} \mathrm{C}$ with standard rat food pellets (Lactamin AB, Stockholm, Sweden) and tap water available ad libitum. The animal experiments were approved by the local Ethics Committee for animal studies at Göteborg University.

Experiment 1 In the first dose-response study, 8-weekold C57BL/6 mice were ovariectomized under isoflurane (Baxter Medical AB, Kista, Sweden) anaesthesia. The ovx model for osteoporosis is included in the FDA guidelines for preclinical and clinical evaluation for agents used for the treatment of postmenopausal osteoporosis (Thompson et al. 1995, Andersson et al. 2001). The mice were treated with increasing doses $(0,0 \cdot 01,0 \cdot 1,1 \cdot 0,10$ and $100 \mu \mathrm{g} / \mathrm{kg}$ per day; $n=5$ mice per group) of E2 (cyclodextrin encapsulated E2, Sigma) for 2 weeks. E2 was administered using s.c. implanted osmotic minipumps (Model 1002, Alzet, Cupertino, CA, USA). Control mice received infusion of the vehicle (20\% (w/v) 2-hydroxypropyl- $\beta$-cyclodextrin, Sigma) (Yaksh et al. 1991).

Experiment 2 In the second study, the dose-response effect of i.c.v. infused E2 was compared with the doseresponse effect of s.c. infused E2. 214 8-week-old C57BL/6 mice (Taconic) were ovariectomized under isoflurane anaesthesia. One week after ovariectomy the mice were anaesthetized with isoflurane and a brain infusion cannula (Alzet) was stereotaxically implanted into the left ventricle using the following coordinates from Bregma: $0.46 \mathrm{~mm}$ posterior, $1.0 \mathrm{~mm}$ lateral and $2.2 \mathrm{~mm}$ ventral (Hof et al. 2000). The brain infusion cannula was secured with two supporting screws and acrylic dental cement (AgnTho's, Lidingö, Sweden) to the calvarial surface. The brain infusion cannula was connected to a dorsally implanted s.c. osmotic minipump (Alzet) with a polyvinylchloride tube (Alzet). In addition, a second osmotic minipump was implanted s.c. on the back of each mouse (for peripheral administration). The mice were treated for 12 days with increasing doses $(0,0 \cdot 01,0 \cdot 03$, $0 \cdot 1,0 \cdot 3,1 \cdot 0,3,30$ and $100 \mu \mathrm{g} / \mathrm{kg}$ per day) of E2 (cyclodextrin encapsulated E2, Sigma) or vehicle $(20 \%$ (w/v) 2-hydroxypropyl- $\beta$-cyclodextrin, Sigma) (Yaksh et al. 1991) via either the central (i.c.v.) or the peripheral (s.c.) route of administration. In order to avoid confounding factors, all animals received continuous infusion via both administration routes simultaneously (i.e. E2 i.c.v. and vehicle s.c. or vice versa).

Experiment 3 In the third study, 13-week-old C57/BL6 mice (M\&B, Uppsala, Sweden) were ovariectomized two weeks before the start of treatment. The treatment groups ( $n=7-10$ mice per group) were: (i) ovx +vehicle (Miglyol 812 (fractionated coconut oil), Recip AB, Årsta, Sweden); (ii) ovx $+\mathrm{E} 2(30 \mu \mathrm{g} / \mathrm{kg}$ per day, Sigma); ovx +ICI 182,780 $(8.3 \mathrm{mg} / \mathrm{kg}$ per day; Tocris Cookson Ltd, Bristol, UK) and ovx+E2+ICI 182,780. The drugs were administered s.c. on a daily basis during 3 weeks. Organs and tissues were removed and wet weights recorded. The left femur and tibia were dissected out and fixed in 10\% formalin, washed thoroughly and stored in 70\% ethanol until bone density measurements were performed.

\section{Peripheral Quantitative Computerized Tomography (pQCT)}

pQCT was performed with the Stratec pQCT XCT Research M (v5.4B; Stratec Medizintechnik GmbH, Pforzheim, Germany) operating at a resolution of $70 \mu \mathrm{m}$ as previously described (Windahl et al. 1999, Andersson et al. 2001). Trabecular bone mineral density (BMD) was determined ex vivo, with a metaphyseal $\mathrm{pQCT}$ scan of the proximal tibia. The scan was positioned in the proximal tibial metaphysis at a distance corresponding to $3 \%$ of the total length of the tibia, in the distal direction from the proximal growth plate. The trabecular bone region was defined as the inner $45 \%$ of the total cross-sectional area. Cortical bone mineral content (BMC) was determined ex vivo with a mid-diaphyseal $\mathrm{pQCT}$ scan of the femur.

\section{Statistical analyses}

All data are presented as mean \pm S.E.M. Differences in E2 sensitivity between different tissues were tested using two-way ANOVA in which dose and tissue were regarded as separate treatments. Differences between i.c.v. and s.c. administration were tested using two-way ANOVA in which dose and administration route were regarded as separate treatments. Differences in E2 response with or without ICI 182,780 were calculated by Student's t-test. 
Table 1 Effect of a high dose $17 \beta$-estradiol $(100 \mu \mathrm{g} / \mathrm{kg}$ per dose) on well known estrogen-responsive tissues. Values are means \pm S.E.M. ( $n=5$ mice per group). Statistical significance was assessed for the difference between vehicle treatment and $17 \beta$-estradiol (E2) treatment

\begin{tabular}{|c|c|c|}
\hline & Ovx + vehicle & Ovx $+E 2$ \\
\hline Uterine weight (mg) & $17 \cdot 4 \pm 0 \cdot 6$ & $129 \cdot 2 \pm 9 \cdot 1^{* * *}$ \\
\hline Trabecular BMD $\left(\mathrm{mg} / \mathrm{cm}^{3}\right)$ & $140 \pm 17$ & $367 \pm 5 \cdot 5^{* * *}$ \\
\hline Cortical BMC (mg/mm) & $0.85 \pm 0.03$ & $1 \cdot 02 \pm 0.06^{*}$ \\
\hline Retroperitoneal fat weight $(\mathrm{mg})$ & $134 \pm 22$ & $52 \cdot 8 \pm 5 \cdot 1^{* *}$ \\
\hline Thymus weight (mg) & $75 \cdot 8 \pm 6 \cdot 6$ & $18 \cdot 6 \pm 1 \cdot 0^{* * *}$ \\
\hline
\end{tabular}

${ }^{*} P<0 \cdot 05 ;{ }^{* *} P<0 \cdot 01 ;{ }^{* * *} P<0 \cdot 001$ (Students $t$-test).

\section{Results}

\section{Tissue sensitivity for E2 treatment}

The effects of a high dose of peripherally administered E2 $(100 \mu \mathrm{g} / \mathrm{kg}$ per day) on several well known estrogen responsive tissues were first investigated in ovx mice. As expected, the E2 treatment increased the uterine weight ( $743 \%$ of vehicle), the trabecular BMD (262\% of vehicle) and the cortical BMC (121\% of vehicle) while it reduced the weights of the retroperitoneal fat depot $(39 \%$ of vehicle) and the thymus (25\% of vehicle, Table 1). The affect of estrogen on cortical BMC was due to an effect on cortical bone size while cortical volumetric BMD was unaffected (data not shown). In addition, dose-response experiments of the effect of peripherally administered E2 on these estrogen-responsive tissues were performed
(Figure 1). These experiments demonstrated that the uterus $\left(\mathrm{ED}_{50} 0.9 \mu \mathrm{g} / \mathrm{kg}\right.$ per day) and the cortical bone $\left(\operatorname{ED}_{50} 0.9 \mu \mathrm{g} / \mathrm{kg}\right.$ per day) were the most sensitive tissues with regard to E2 treatment. In contrast, the trabecular bone $\left(\mathrm{ED}_{50} 12 \mu \mathrm{g} / \mathrm{kg}\right.$ per day) was more than 10 times less sensitive than the uterus and the cortical bone $(P<0 \cdot 01)$. The estrogen sensitivity was intermediate for the effects of $\mathrm{E} 2$ on thymus weight $\left(\mathrm{ED}_{50} 1.9 \mu \mathrm{g} / \mathrm{kg}\right.$ per day) and retroperitoneal fat weight $\left(\mathrm{ED}_{50} 1.7 \mu \mathrm{g} / \mathrm{kg}\right.$ per day; Fig. 1). Thus, the uterus and the cortical bone were the most sensitive tissues, thymus and retroperitoneal fat were of intermediate sensitivity and trabecular bone was the least sensitive tissue with regard to E2 treatment.

\section{Comparison of the dose-response effects of centrally versus} peripherally administered E2

To investigate whether the effects of $\mathrm{E} 2$ on the above mentioned estrogen-responsive tissues were primarily mediated via a central mechanism, ovx mice were treated with increasing doses of E2 administered either s.c. or i.c.v. We hypothesized that a centrally mediated effect of E2 should result in a left shift of the dose-response curve for i.c.v. administration compared with s.c. administration (i.e. $\mathrm{ED}_{50}$ for i.c.v. should be lower than $\mathrm{ED}_{50}$ for s.c.), while no such left shift should occur for a peripheral effect. No significant difference between the s.c. and i.c.v. route of administration was seen for the effect of E2 on uterine weight, thymus weight, trabecular BMD or cortical bone (two-way ANOVA). Thus, the dose-response curves for centrally versus peripherally administered E2 did not

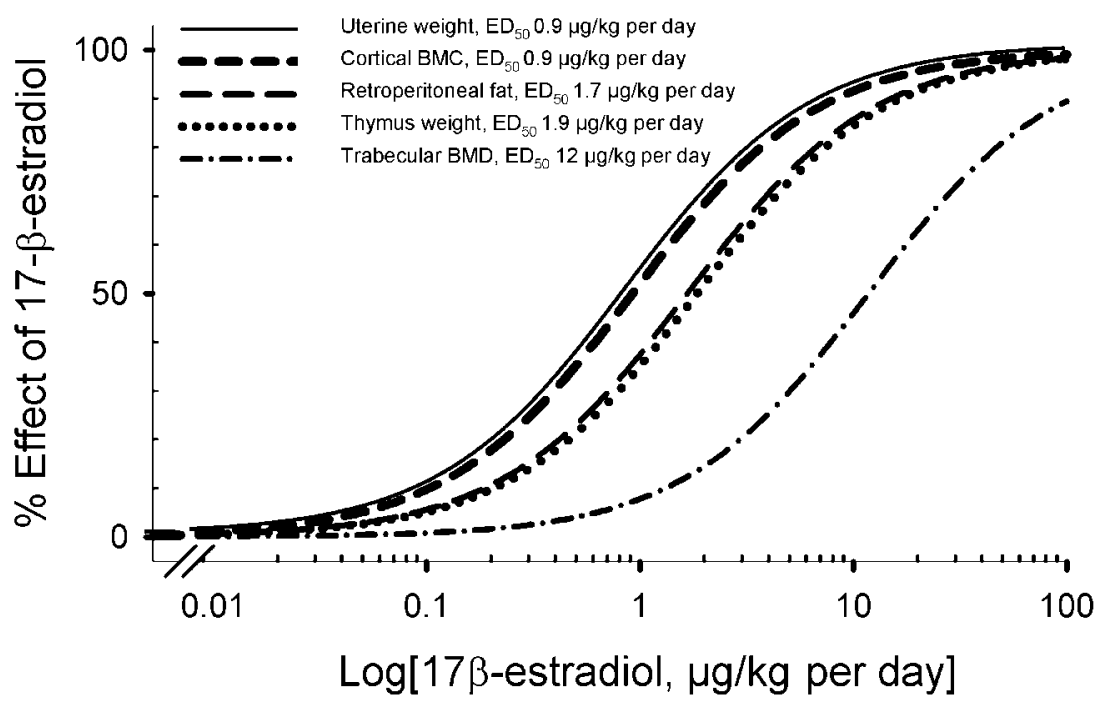

Figure 1 Tissue sensitivity for estradiol treatment. The dose-response effect of peripherally administered E2 was determined in estrogen responsive target organs. All organs responded in a dose-dependent manner to E2. Estrogen increased uterine weight, cortical bone mineral content (BMC) and trabecular bone mineral density (BMD) while it decreased retroperitoneal fat weight and thymus weight. Values are expressed as a \% of the maximal effect of E2. 
A Uterine weight

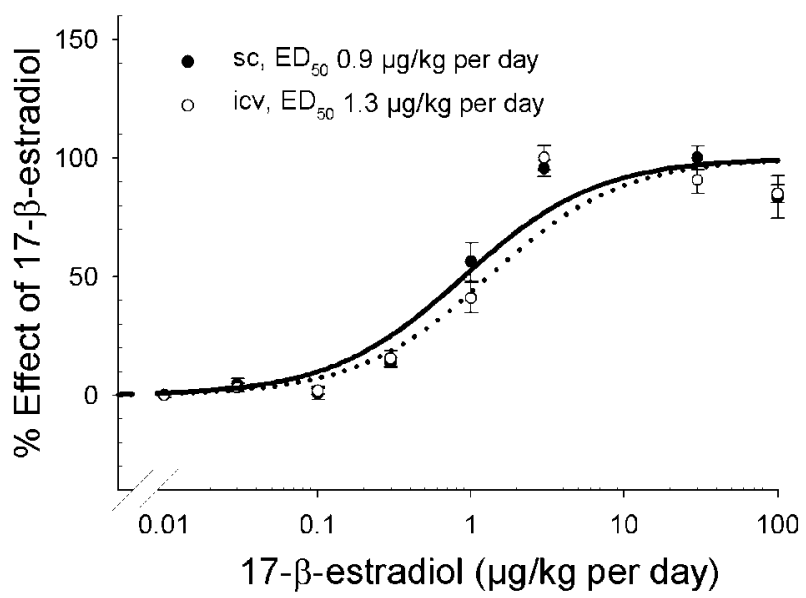

C Trabecular BMD

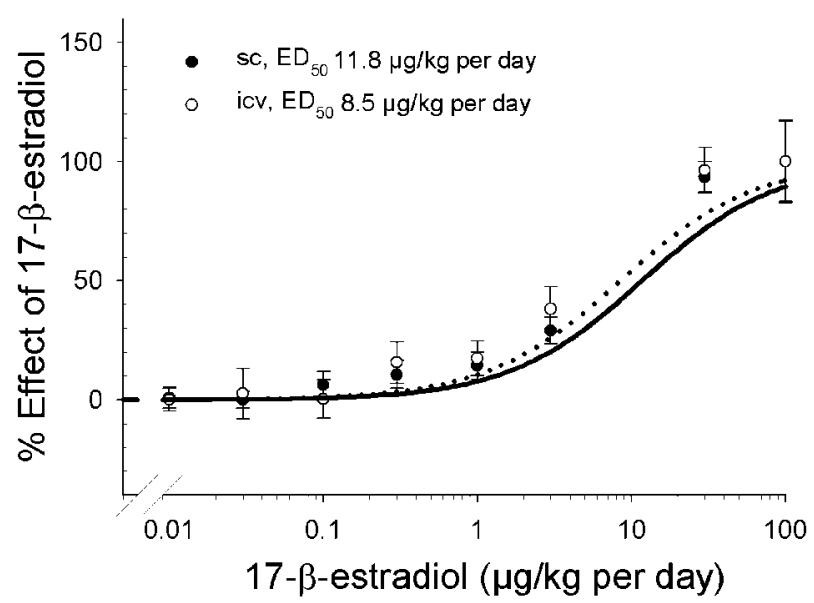

\section{B Thymus weight}

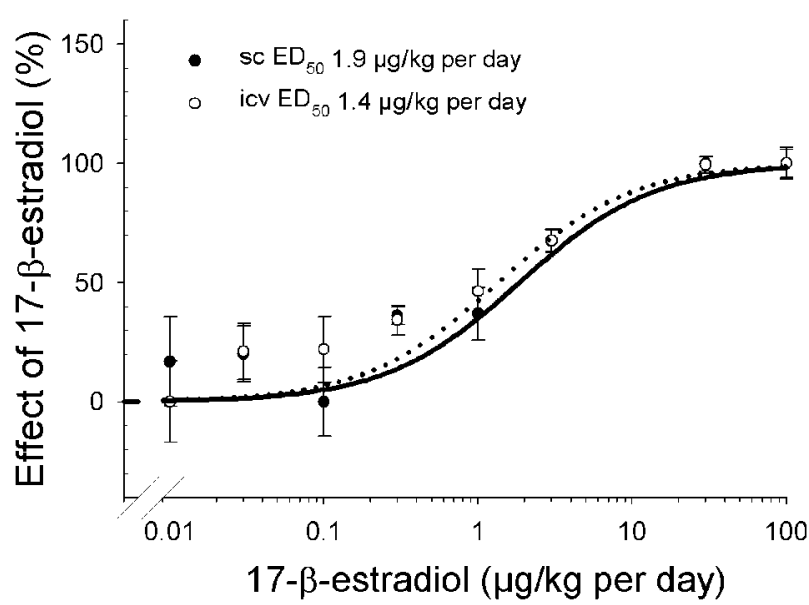

Cortical BMC

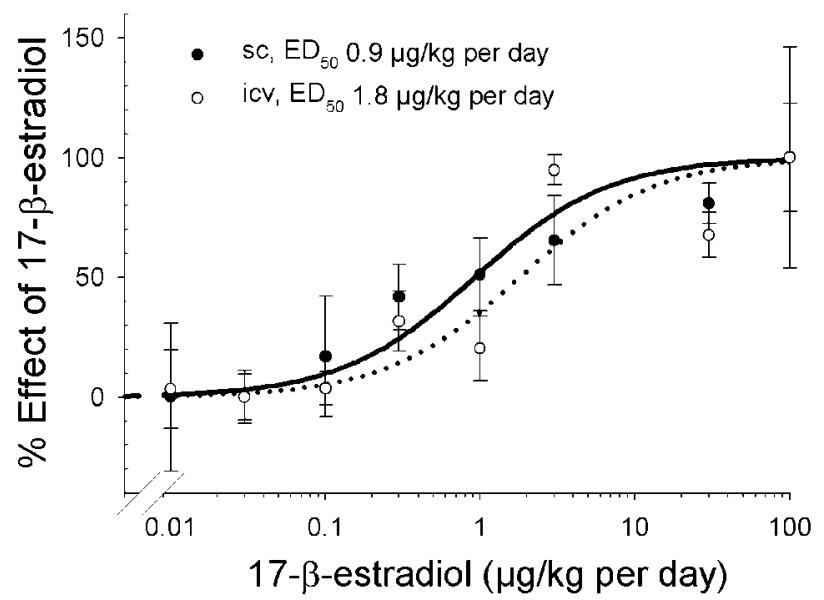

Figure 2 Comparison of the dose-response effects of central versus peripheral administered E2. Dose-response effect of $17 \beta$-estradiol following peripheral (s.c.) and central (i.c.v.) administration of $17 \beta$-estradiol on (A) uterine weight, (B) thymus weight (C) trabecular bone mineral density (BMD) and (D) cortical bone mineral content (BMC). Ovx mice were treated with various doses of $17 \beta$-estradiol for 14 days. $17 \beta$-estradiol was administered either through the s.c. or the i.c.v. route using subcutaneously implanted osmotic minipumps. Values are expressed as a mean \pm S.E.M \% of maximal effect of $17 \beta$-estradiol.

differ for any of the studied estrogen-responsive tissues (Fig. 2).

Investigation of central versus peripheral E2 effects, using a peripheral estrogen receptor antagonist (ICI 182,780)

The central versus peripheral estrogen effects on selected estrogen responsive tissues were also investigated using an alternative approach. Ovx mice were treated with E2 $(30 \mu \mathrm{g} / \mathrm{kg}$ per day, and/or the estrogen receptor antagonist
ICI $182,780(8.3 \mathrm{mg} / \mathrm{kg}$ per day). It has previously been shown that ICI 182,780 does not pass the blood-brain barrier ((BBB) Wakeling et al. 1991, Wakeling \& Bowler 1992, Wade et al. 1993, DeFriend et al. 1994, Thomas et al. 1994). Thus, ICI 182,780 is a peripheral estrogen receptor antagonist. As expected, the E2 treatment increased the uterine weight $(1428 \pm 90 \%$ of vehicle, $P<0 \cdot 05)$, the trabecular BMD $(131 \pm 6 \%$ of vehicle, $P<0 \cdot 05)$ and the cortical BMC $(109 \cdot 6 \pm 1 \cdot 8 \%$ of vehicle, $P<0.05)$ while it reduced the weight of the 


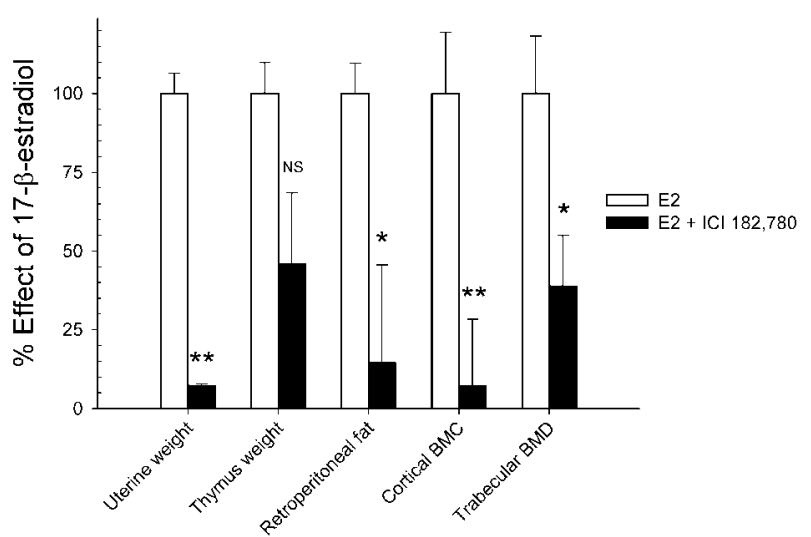

Figure 3 Investigation of central versus peripheral E2 effects, using a peripheral estrogen receptor antagonist (ICl 182,780). The effects of E2 in the absence or presence of estrogen receptor antagonists were compared. Values are expressed as mean \pm S.E.M. $\%$ effect of E2 in estrogen treated ovx mice compared with vehicle treated $(n=7-10) .{ }^{*} P<0 \cdot 05, * * P<0 \cdot 01$ E2 versus $\mathrm{E} 2+\mathrm{ICl} 182,780$ students $t$-test.

retroperitoneal fat depot (47 $\pm 6 \%$ of vehicle, $P<0 \cdot 05)$ and the thymus $(53 \pm 5 \%$ of vehicle, $P<0 \cdot 05)$. We then calculated to which extent ICI 182,780 could attenuate the response to E2 in these tissues. A high degree of attenuation would indicate that the effect on the specific tissue is peripherally mediated (PM) since the estrogen antagonist does not cross the BBB. ICI 182,780 attenuated most of the estrogenic response regarding uterus weight (PM $\geq 92 \%, P<0 \cdot 05$ ), retroperitoneal fat weight (PM $\geq 85 \%, P<0 \cdot 05)$, cortical BMC (PM $\geq 92 \%, P<0 \cdot 05)$ and trabecular BMD (PM $\geq 61 \%, P<0 \cdot 05)$ while the attenuation was intermediate for the thymus (PM $\geq 54 \%$, not significant, Fig. 3).

\section{Discussion}

Besides being important for the reproductive system, estrogens are of importance for the regulation of the bone mass as demonstrated by the pronounced bone loss in various estrogen deficient states, such as postmenopausal osteoporosis and after ovariectomy (Riggs et al. 2002). Despite extensive studies, the exact mechanism behind ovx-induced bone loss is not fully understood. It is generally believed that estrogens exert their bone sparing effects directly on the cells within the bone compartment. The bone sparing effects of estrogen in rodents are believed not only to be mediated through inhibition of bone resorption, but also through stimulation of bone formation (Chow et al. 1992). However, some studies indicate that the effects of estrogens on bone are indirect and may include central mechanisms (Yeh et al. 1997, Baldock et al. 2002, Takeda et al. 2002, Bohlooly et al. 2004, Sainsbury et al. 2003, Vanderschueren et al. 2004).
Our present findings support the concept that most of the E2 effect on bone is primarily mediated via peripheral and not central estrogen receptors.

We first investigated the magnitude and the sensitivity of the E2 effect in different estrogen responsive tissues when E2 was administered peripherally (s.c.). As expected the largest estrogen response compared with control was seen for the uterine weight and for the trabecular BMD, while the maximal response for the cortical BMC and on fat mass was of minor magnitude but still highly statistically significant. However, regarding the sensitivity for E2, it was shown that the uterus and the cortical bone were the most sensitive tissues while the trabecular bone was more than 10 times less sensitive (lower $\mathrm{ED}_{50}$ value for cortical bone and uterus than in trabecular bone). The sensitivity of fat and thymus was intermediate. Thus, a different tissue pattern was observed for the maximal magnitude of E2 response compared with the sensitivity to E2. The higher sensitivity for E2 in cortical bone than in trabecular bone might indicate that the mechanism of action for E2 in these two bone compartments differs. However, one can not exclude that the biological and clinical relevance of a specific dose of estradiol on trabecular BMD (with a relatively high $\mathrm{ED}_{50}$ ) might be of more importance than that on cortical BMC (with a relatively low $\mathrm{ED}_{50}$ ), due to the fact that the maximal response is much higher for trabecular BMD than that for cortical BMC. It has previously been suggested that the cortical BMC but not the trabecular BMD is dependent on circulating IGF-I (Sjögren et al. 2002) and, therefore, one might speculate that the stimulatory E2 effect on cortical bone (but not that on trabecular bone) is IGF-I-dependent.

Since the ovariectomized mouse model is frequently used for the tissue specific evaluation of selective estrogen receptor modulators, the need for a well characterized mouse model becomes apparent. The present study provides important information regarding the dose-response of estrogen on several estrogen-responsive tissues, including the uterus, the thymus, the retroperitoneal fat depot as well as the cortical and the trabecular bone compartments separately. Furthermore, due to the development of a large number of genetically engineered mouse models, the ovariectomized mouse model has been frequently used as an animal model for postmenopausal osteoporosis (Lindberg et al. 2002, Hikiji et al. 2004, Usui et al. 2004). It is therefore surprising that very few studies have characterized the dose-response effect of E2 in different tissues in this model (Mödder et al. 2004). Most of the genetically engineered mouse models have been bred to the C57BL/6 background strain. Thus, the mouse in general and the C57BL/6 strain in particular, needs to be further characterized with respect to the dose-response of estrogens in different tissues. In a recent study, the dose-response of E2 was studied in C57BL/6 mice (Mödder et al. 2004). This study demonstrated that the relative effects of E2 on bone and the uterus are highly 
dependent on the particular experimental conditions used, with a relatively high uterine E2 sensitivity in 3-monthold mice but a relatively low uterine E2 sensitivity in 6-month-old mice (Mödder et al. 2004). In the present study, using 2-month-old C57BL/6 mice, we found that the uterus was highly E2 sensitive compared with the trabecular bone. Although we may not be able to compare these studies, it seems clear that the uterus in young mice is more sensitive to E2 than that of older mice whereas the estrogenic response in bone is not so much affected by age.

In the present study, we hypothesized that a centrally mediated effect of E2 on a tissue should result in a left shift of the dose-response curve for i.c.v. administration compared with s.c. administration (i.e. $\mathrm{ED}_{50}$ for i.c.v. should be lower than $\mathrm{ED}_{50}$ for s.c.), while no such left shift should occur for a peripherally mediated effect. The doseresponse curves for central, compared with the peripheral administration of E2 did not differ for any of the studied estrogen-responsive tissues, supporting the notion that these effects were mainly peripherally mediated. Our second approach demonstrated that the peripheral estrogen receptor antagonist ICI 182,780 attenuated most of the estrogenic response regarding uterine weight, retroperitoneal fat weight, cortical BMC and trabecular BMD, further supporting the notion that the primary target tissues for the mediation of the effect of E2 are peripheral and not central.

In this study, we have used s.c. implanted osmotic minipumps to deliver E2 to the mice. The osmotic minipumps can deliver a constant dose of E2 with a plasma profile similar to that of a slow release pellet, which is commonly used in long-term in vivo studies (Fara \& Urquhart 1984, Ebling et al. 2000). The major advantage of using osmotic minipumps is that they can be connected to a brain infusion cannula, enabling continuous long term i.c.v. administration. Thus, with the minipumps we were able to avoid much of the daily handling trauma and anesthesia that would occur if the mice would have been given daily i.c.v. injections. A limitation with the present study is that the effects of central and peripheral estradiol treatment on food intake and GH-secretion, which might be involved in some of the estrogenic effect on bone, not were analysed.

In conclusion, the sensitivity for E2 is tissue-dependent and our findings indicate that the primary target tissue for the mediation of the effect of E2 on bone is peripheral and not central.

\section{Acknowledgements}

The authors extend their appreciation to Anette Hansevi and Maud Petersson for their technical assistance. We would also like to thank the SWEGENE Center for Bio-Imaging (CBI) for technical support regarding image analysis.

\section{Funding}

This study was supported by the Swedish Research Council, the Swedish Foundation for Strategic Research, the Tore Nilson Foundation, SWEGENE, European Commission Grant QLK4-CT-2002-02528, the Lundberg Foundation, the Torsten and Ragnar Söderberg's Foundation, Petrus and Augusta Hedlunds Foundation and the Novo Nordisk Foundation. The authors declare that there is no conflict of interest that would prejudice the impartiality of this scientific work.

\section{References}

Andersson N, Lindberg MK, Ohlsson C, Andersson K \& Ryberg B 2001 Repeated in vivo determinations of bone mineral density during parathyroid hormone treatment in ovariectomized mice. Journal of Endocrinology 170 529-537.

Baldock PA, Sainsbury A, Couzens M, Enriquez RF, Thomas GP, Gardiner EM \& Herzog H 2002 Hypothalamic Y2 receptors regulate bone formation. Journal of Clinical Investigation 109 915-921.

Bohlooly YM, Mahlapuu M, Andersen H, Åstrand A, Hjorth S, Svensson L, Törnell J, Snaith MR, Morgan DG \& Ohlsson C 2004 Osteoporosis in MCHR1-deficient mice. Biochemical and Biophysical Research Communications 318 964-969.

Bryant HU, Magee DE, Cole HW, Chandrasekhar S, Hsuing HM, Heiman ML \& Sato M 1994 Beneficial effects of ethinyl estradiol (EE2) and raloxifene in ovariectomized (OVX) rat are dependent on an intact pituitary. Journal of Bone and Mineral Research 9 S135.

Chow J, Tobias JH, Colston KW \& Chambers TJ 1992 Estrogen maintains trabecular bone volume in rats not only by suppression of bone resorption but also by stimulation of bone formation. Journal of Clinical Investigation 89 74-78.

Clark AS, Kelton MC, Guarraci FA \& Clyons EQ 2004 Hormonal status and test condition, but not sexual experience, modulate partner preference in female rats. Hormones and Behavior $\mathbf{4 5}$ 314-323.

DeFriend DJ, Howell A, Nicholson RI, Anderson E, Dowsett M, Mansel RE, Blamey RW, Bundred NJ, Robertson JF \& Saunder C 1994 Investigation of a new pure antiestrogen (ICI 182,780) in women with primary breast cancer. Cancer Research 54 408-414.

Ebling FJ, Brooks AN, Cronin AS, Ford H \& Kerr JB 2000 Estrogenic induction of spermatogenesis in the hypogonadal mouse. Endocrinology 141 2861-2869.

Fara J \& Urquhart J 1984 The value of infusion and injection regimens in assessing efficacy and toxicity of drugs. 521.

Hikiji H, Ishii S, Shindou H, Takato T \& Shimizu T 2004 Absence of platelet-activating factor receptor protects mice from osteoporosis following ovariectomy. Journal of Clinical Investigation 114 85-93.

Hof PR, Young WG, Bloom FE, Belichenko PV \& Celio MR 2000 Comparative cytoarchitectonic atlas of the C57BL/6 and 129/Sv mouse brains. Amsterdam: Elsevier.

Lindberg MK, Weihua Z, Andersson N, Movérare S, Gao H, Vidal O, Erlandsson M, Windahl S, Andersson G, Lubahn DB et al. 2002 Estrogen receptor specificity for the effects of estrogen in ovariectomized mice. Journal of Endocrinology 174 167-178.

Mödder UI, Riggs BL, Spelsberg TC, Fraser DG, Atkinson EJ, Arnold R \& Khosla S 2004 Dose-response of estrogen on bone versus the uterus in ovariectomized mice. European Journal of Endocrinology 151 503-510.

Riggs BL, Khosla S \& Melton LJ, 3rd 2002 Sex steroids and the construction and conservation of the adult skeleton. Endocrine Reviews 23 279-302. 
Sainsbury A, Baldock PA, Schwarzer C, Ueno N, Enriquez RF, Couzens M, Inui A, Herzog H \& Gardiner EM 2003 Synergistic effects of Y2 and Y4 receptors on adiposity and bone mass revealed in double knockout mice. Molecular Cell Biology 23 5225-5233.

Sjögren K, Sheng M, Movérare S, Liu JL, Wallenius K, Törnell J, Isaksson O, Jansson JO, Mohan S \& Ohlsson C 2002 Effects of liver-derived insulin-like growth factor I on bone metabolism in mice. Journal of Bone andMineral Research 17 1977-1987.

Takeda S, Elefteriou F, Levasseur R, Liu X, Zhao L, Parker KL, Armstrong D, Ducy P \& Karsenty G 2002 Leptin regulates bone formation via the sympathetic nervous system. Cell 111 305-317.

Thomas EJ, Walton PL, Thomas NM \& Dowsett M 1994 The effects of ICI 182,780, a pure anti-oestrogen, on the hypothalamic-pituitary-gonadal axis and on endometrial proliferation in pre-menopausal women. Human Reproduction 9 1991-1996.

Thompson DD, Simmons HA, Pirie CM \& Ke HZ 1995 FDA Guidelines and animal models for osteoporosis. Bone 17 125S-133S.

Usui M, Yoshida Y, Tsuji K, Oikawa K, Miyazono K, Ishikawa I, Yamamoto T, Nifuji A \& Noda M 2004 Tob deficiency superenhances osteoblastic activity after ovariectomy to block estrogen deficiency-induced osteoporosis. PNAS 101 6653-6658.

Wade GN, Blaustein JD, Gray JM \& Meredith JM 1993 ICI 182,780: a pure antiestrogen that affects behaviors and energy balance in rats without acting in the brain. American Journal of Physiology $\mathbf{2 6 5}$ R1392-R1398.
Wakeling AE \& Bowler J 1992 ICI 182,780, a new antioestrogen with clinical potential. Journal of Steroid Biochemistry and Molecular Biology 43 173-177.

Wakeling AE, Dukes M \& Bowler J 1991 A potent specific pure antiestrogen with clinical potential. Cancer Research 51 3867-3873.

Vanderschueren D, Vandenput L, Boonen S, Lindberg MK, Bouillon R \& Ohlsson C 2004 Androgens and bone. Endocrine Reviews 25 389-425.

Windahl SH, Vidal O, Andersson G, Gustafsson JÅ \& Ohlsson C 1999 Increased cortical bone mineral content but unchanged trabecular bone mineral density in female ERbeta(-/-) mice. Journal of Clinical Investigation 104 895-901.

Yaksh TL, Jang J, Nishiuchi Y, Braun KP, Ro S \& Goodman M 1991 The utility of 2-hydroxypropyl-[beta]-cyclodextrin as a vehicle for the intracerebral and intrathecal administration of drugs. Life Sciences 48 623-633.

Yeh JK, Chen MM \& Aloia JF 1997 Effects of 17 beta-estradiol administration on cortical and cancellous bone of ovariectomized rats with and without hypophysectomy. Bone 20 413-420.

Received in final form 10 June 2005

Accepted 5 August 2005 
